\title{
ASSESSMENT OF THE SHADOW ECONOMY DEVELOPMENT TENDENCIES IN THE SVERDLOVSK REGION
}

The paper deals with analysis of shadow economy dynamics in the Sverdlovsk region. The analysis covers the period since 2001 to 2009, and it also concerns medium and long term since 2011 to 2020.

\footnotetext{
${ }^{1}$ The research was accomplished within the framework of the state contract № П903 of August 18, 2009, under the competition "Exploration and research work in "Economics" in the context of the procedure 1.2.1. of the research Programme (НК-71П): "Shadow economy as a threat to sustainable development. Analysis and opposition activities"
}

In the course of the analysis economic and mathematical models of shadow economy in the context of changing socio-economic environment have been applied. For the medium- and long-term analysis the record of economic, social and technological factors' influence on the shadow sector of economy of the Sverdlovsk region was used.

For the long-term analysis of shadow economic dynamics key scenarios of economic development with 
generation of base cases of further transformation of the shadow sector of economy have been considered. Inertial, innovation and optimistic development alternatives have been considered as basic scenarios of economic development in posse.

A complex of steps aimed at reduction of the shadow sector segment in the medium-and long-term outlook has been suggested.

Solution of wide-ranging tasks concerned with enhancement of the living standard and dynamic development of economy in the long-term prospect, consolidation of a stand of the Sverdlovsk region among the Constituent Entities of the Russian Federation and the world community, is impossible without an up-to-date market infrastructure development. It is the only case when qualitative growth of economy is possible based not only on mineral resource exports, but also innovations and modern enterprise development.

To achieve of the above-named goals, a number of tasks are to be solved; one of the major tasks is opposition to shadow economic activity and minimization of shadow economy impact on the regional economy.

A technique intended for assessment of regional economy damage caused by shadow economy developed at the Institute of Economics UB RAS was applied for evaluation of shadow economy impact on the socio-economic condition of the Ural Federal District in 2001-2010 [1].

In 2001-2006 reduction of the shadow economy damage had been observed (Table 1); however, in 2007-2008 growth of the shadow economy damage to the Constituent Entities of the UFD had been conspicuous. Thus, growth of damage in 2007-2008 in relation to the previous year amounted to 25.3 and $36.4 \%$ correspondingly.

Shadow economy is a certain indicator, a touchstone demonstrating general state of economy.

Thus, the Sverdlovsk region, along with other UFD subjects, experienced a detrimental effect of the crisis trends in the economy in Russia in the third quarter of 2008 [2].

So far as the region is among the key industrial regions of Russia, a drop in industrial output had an adverse effect on economic development dynamics: since July, 2008 an index of industrial production had been reduced, and that resulted in negative dynamics of the given indicator throughout 2009 (according to the outcome of 2009, the index of industrial production did not exceed $83 \%$ ), it was stabilized only at the beginning of 2010 and reached $115 \%$ by the third quarter in relation to the same period of the previous year [3].

The general economic recession was expressed in terms of earnings dilution of enterprises: in 2009 reduction of tax payment in terms of the income tax amounted to over $50 \%$ (with account for tax rate change) [4]. As consequence, considerable growth in number of shadow operations concerned with fictitious expenditure and concealment of income in the general structure of the tax base is observed: from $30 \%$ in the third quarter of 2008 to $55 \%$ in the third quarter of 2009 (Figure 1) was observed.

Figure 1 illustrates a distinctive feature of shadow economy - instant growth due to deterioration of socio-economic and institutional conditions of economic activity and long period of turnaround.

The beginning of the stabilization period in the economy falls within the IV quarter of 2009 - I quarter of 2010. Owing to improvement of financial

Table 1

Ratio of the shadow economy damage to the gross regional product, $\%$

\begin{tabular}{|l|c|c|c|c|c|c|c|}
\hline Year & UFD & Kurgan region & $\begin{array}{c}\text { Sverdlovsk } \\
\text { region }\end{array}$ & $\begin{array}{c}\text { Chelyabinsk } \\
\text { region }\end{array}$ & $\begin{array}{c}\text { Tyumen re- } \\
\text { gion (without } \\
\text { autonomous } \\
\text { districts) }\end{array}$ & $\begin{array}{c}\text { Khanty- } \\
\text { Mansijsk } \\
\text { Autonomous } \\
\text { District }\end{array}$ & $\begin{array}{c}\text { Yamal-Nenets } \\
\text { Autonomous } \\
\text { District }\end{array}$ \\
\hline 2001 & 21.62 & 38.13 & 32.92 & 33.31 & 37.34 & 14.11 & 13.01 \\
\hline 2002 & 20.26 & 43.99 & 28.41 & 31.24 & 39.16 & 12.73 & 13.20 \\
\hline 2003 & 19.28 & 39.65 & 29.23 & 33.68 & 33.15 & 10.35 & 13.39 \\
\hline 2004 & 23.77 & 36.59 & 30.06 & 32.78 & 36.57 & 15.21 & 13.77 \\
\hline 2005 & 14.53 & 25.76 & 18.18 & 19.15 & 27.70 & 11.40 & 10.93 \\
\hline 2006 & 12.97 & 26.88 & 17.91 & 18.89 & 24.72 & 9.09 & 8.42 \\
\hline 2007 & 14.96 & 30.05 & 22.44 & 25.62 & 21.53 & 5.76 & 13.81 \\
\hline 2008 & 19.22 & 33.57 & 30.60 & 32.55 & 28.36 & 7.25 & 15.77 \\
\hline 2009 & 18.42 & 32.67 & 29.12 & 32.18 & 27.15 & 7.22 & 15.23 \\
\hline $2010^{*}$ & 18.34 & 32.30 & 28.54 & 31.87 & 26.80 & 7.10 & 14.94 \\
\hline
\end{tabular}

${ }^{*}$ Evaluation data. 


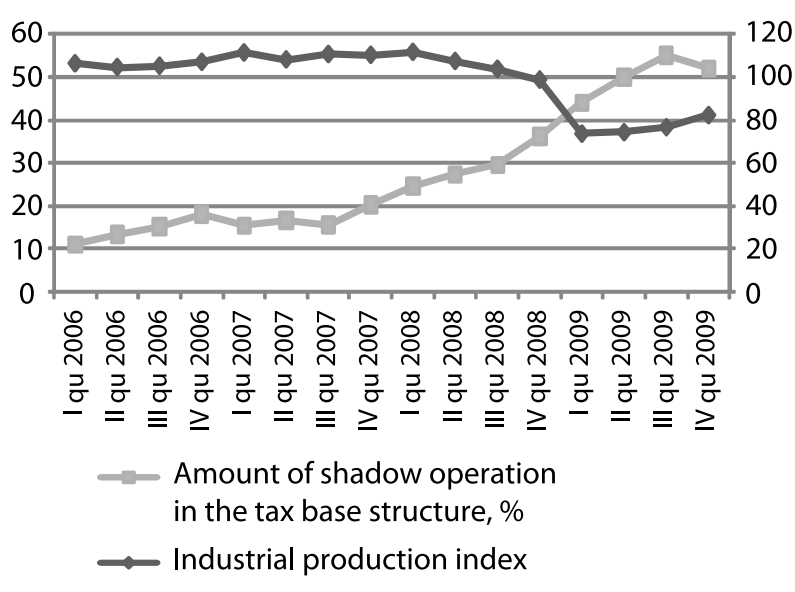

Fig. 1. Amount of shadow activities in the general tax base structure (Sverdlovsk region), \%

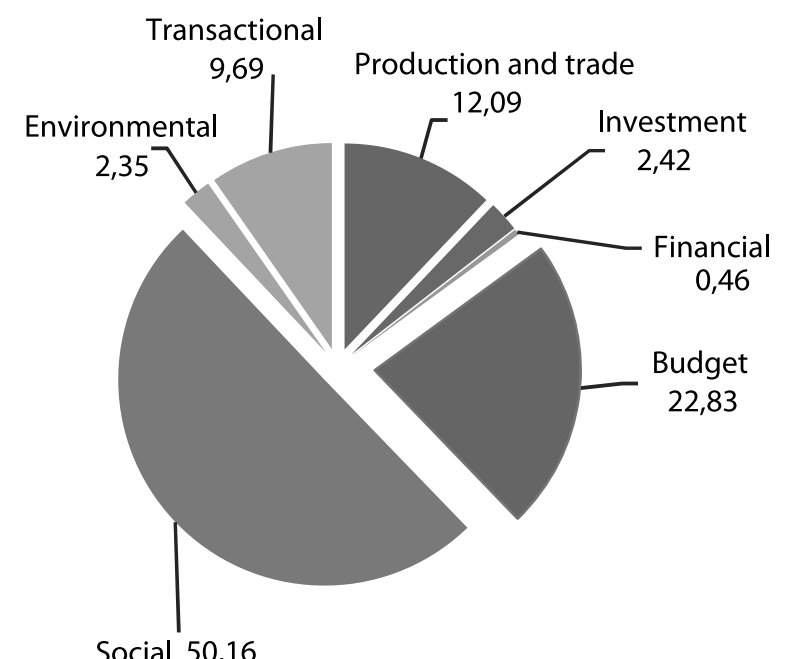

Fig. 2. Structure of damage according to the scopes of activity in the Sverdlovsk region, \% (2009)

performance of business activity by taxpayers (in the issue of the first three quarters of 2010 , revenue increment in terms of the income tax in the Sverdlovsk region amounted to over $80 \%$ as compared to the same period of 2009).

Natural bias to reduction of damage caused by shadow economy was observed in the Sverdlovsk region in 2009 (Table 1).

As follows from the above-mentioned results (Fig. 2), major damage of 2009 was observed in the public sector and social sphere (22.83\% and $50.16 \%$ ).

Such a situation is due to large-scale tax evasion (public sector damage) and, consequently, underfunding of the social sphere.

According to the calculations, the public sector damage is over $50 \%$ of the taxes collected in the territory; that is due to low level of taxes collected in 2009 caused by setback in production and trade turnover and retention of the damage trend in the sector in question.
The rest damage is referred to other spheres, with under $10 \%$ taken by each.

Despite high values of shadow economy damage rates in relation to the GRP, the total damage (in relation to the GRP) is less for the UFD as a whole. That is due to low (in comparison to other UFD subjects) damage rate in relation to the GRP in the Khanty-Mansijsk Autonomous District and the Yamal-Nenets Autonomous District, so far as the contribution of the given UFD subjects to the total amount of the GRP is over $50 \%$.

Growth of the shadow economy damage to the Sverdlovsk region is due to the causes divided into 3 integrated blocks in Fig. 3.

The major causes of the shadow sector growth include the following:

1. Lack of capital assets due to the financial liquidity crisis that affected the banking sector (total past-due debt in loan proceeds increased from 815 million rub. up to 18957 million rub. during the critical stage of the economic crisis - III-IV quarter of 2008, I-II quarter of 2009).

2. Slowdown in performance of enterprises (in the III quarter of 2008 business profits in the Sverdlovsk region amounted to 54 million rub., while the I quarter of 2009 ended in the loss of 19 million rub.; despite a certain improvement of the economic situation in 2010, the II quarter of 2010 was specified by the business profits of only $49 \%$ of the total profit in the II quarter of 2008).

3. Complexity in terms of capital renewals due to the drop of retained profits of business and outflow of financial resources from the region (growth of outward investment by $73 \%$ was observed in the Sverdlovsk region by the end of 2008).

4. Lack of sufficient free financial assets for wage payment (the total past-due debt in wages did not exceed 18 million rub. in the first half-year of 2008, while it reached 200 million rub. in the I quarter of 2009, and only by II-III quarter of 2010 this rate was reduced to the pre-crisis level).

The result of prediction of shadow activity dynamics (economic and mathematical models of shadow economy under changing socio-economic environment were applied for the prediction) demonstrates high probability of further increase of rates until the end of III quarter 2011. Despite general improvement of the economic situation in the Sverdlovsk region as of the beginning of 2010, poor dynamics of industrial production (with industrially-oriented structure of the economy of the Sverdlovsk region taken into consideration) adversely affects the scale of the shadow sector in the region (Fig. 4). 


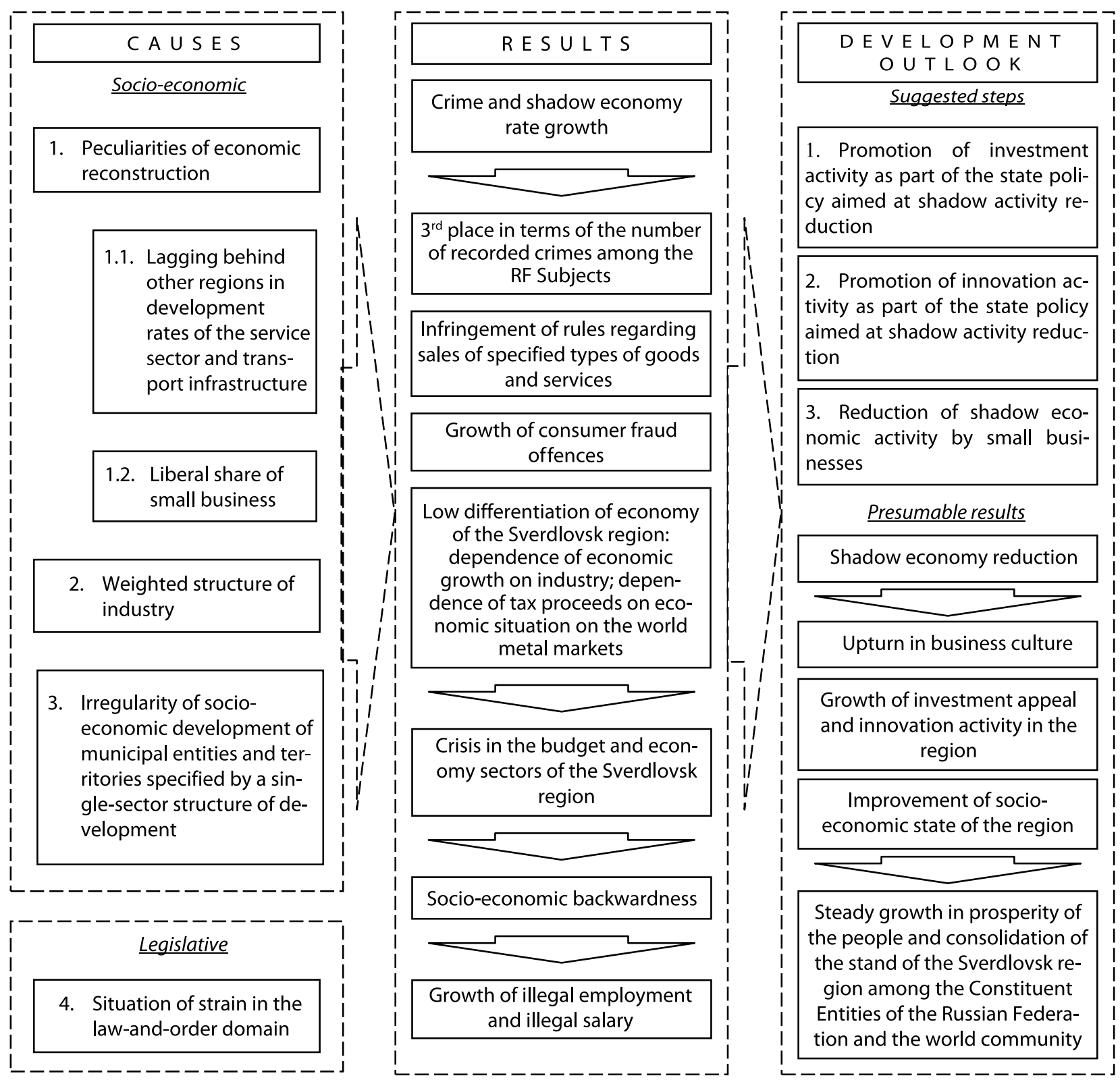

Fig. 3. Causes of shadow economy growth and development outlook

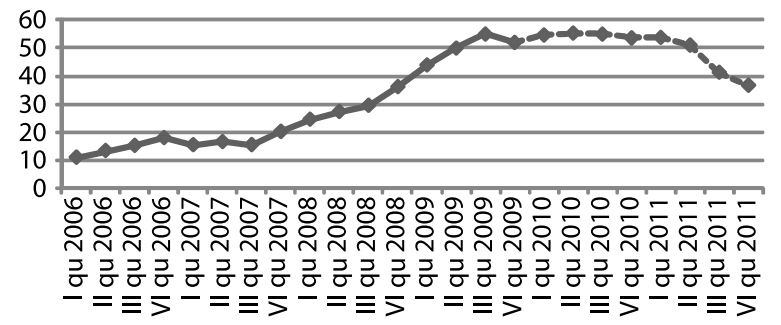

Fig. 4. Prediction of the shadow segment in the business activity of the Sverdlovsk region until 2011, \%

As was demonstrated by the prediction of the shadow economy dynamics, the situation is different in the UFD subjects. Thus, the Kurgan and Sverdlovsk regions, as well as the Yamal-Nenets
Autonomous District, are specified not only by sharp increase in shadow segment during the economic crisis, but also by fast scaling down of the shadow economy at the time of economic stabilization. However, it is unlikely that the scale of the shadow activity will return to the pre-crisis level until the end of 2011; the given assumption is particularly true for the Sverdlovsk region, where the amount of shadow transactions in the structure of tax base has grown from 30 to $70 \%$ during the economic crisis. The given rate was not that high in other UFD subjects in the course of the crisis.

The results of the prediction have demonstrated that despite socio-economic situation improvement observed since the first half of 2010 , the shadow 


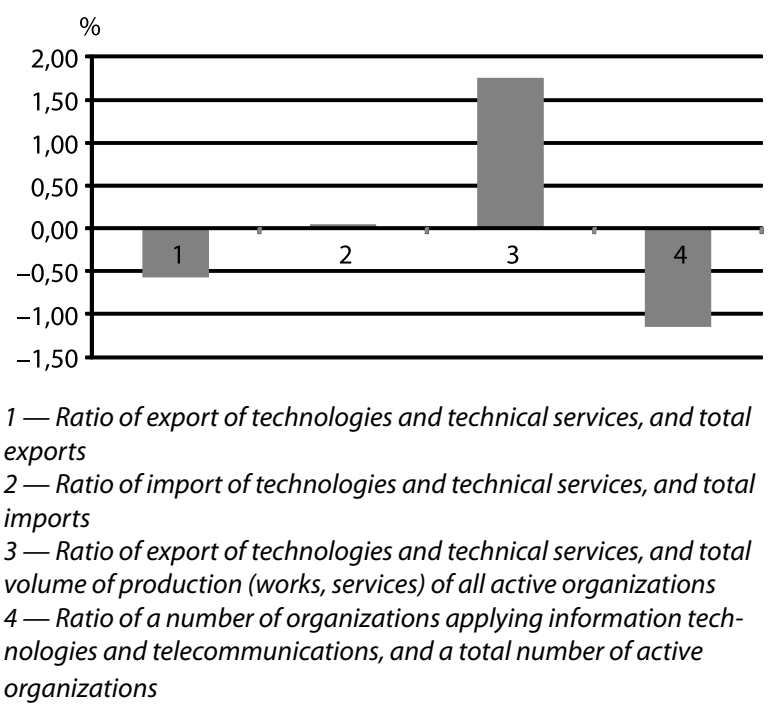

Fig. 5. Percentage variation of shadow economy damage to the economic system of the Sverdlovsk region, under the effect of increase of certain rates specifying an innovation nature of economic environment by $1 \%$

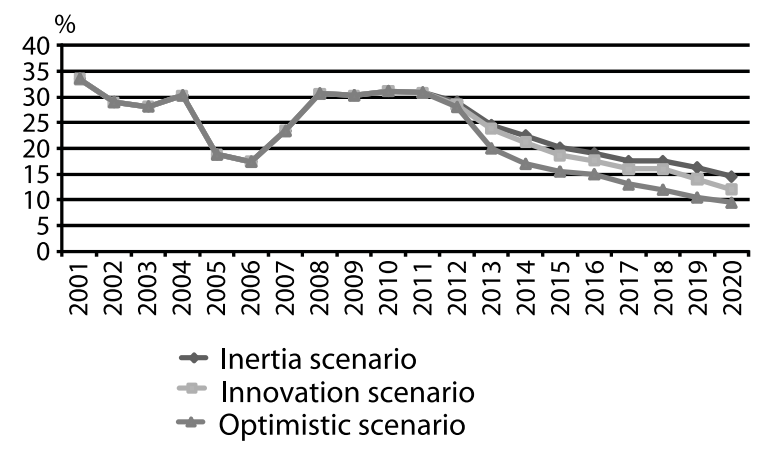

Fig. 6. prediction scenarios of variation of the damage to the economic system of the region until 2020

economy segment retain the crisis level (50-55\%) in the general structure of the tax base of economic entities.

A long-term analysis of shadow economy dynamics is to consider several key scenarios of economic development assuming generation of basic versions of further shadow sector transformations. The basic probable scenarios of economic development include the following:

1. Inertial development - a pursuing case of technological development with the current dynamics of socio-economic processes preserved.

2. Innovation development - reorientation of the national economy to the way of innovation development.

3. Optimistic version of development - assumes intensification of development of innovation branches of economy for account of investment activity growth.

To make predictions, the data on the influence of various economic, social, technological factors on the shadow sector of economy of the Sverdlovsk region were used. The data were obtained in the issue of the analysis of economic and mathematical models of influence of socio-economic and scientific-technical environment on the of shadow activity dynamics. As an example, figure 5 demonstrates a comparative diagram describing the influence of parameters specifying an impact of certain scientific and technical aspects of the Sverdlovsk region on change of the damage to the economic complex of region caused by the shadow economy.

The most adverse effect on the dynamics of the damage to the economic system of the region has such a factor as a number of organizations applying information technologies and telecommunications in relation to the total number of organizations (increase of the given rate by $1 \%$ causes shadow economy damage growth by $1.2 \%$ ). That is due, on the one hand, to the fact that shadow economy is focused on the most profitable and, correspondingly, promising sectors of economy (hi-tech branches are primarily among them). On the other hand, economic entities that are not willing to maintainfinancial discipline, extensively use modern communication systems and information technologies as a tax evasion tool and an instrument of remote administration of shadow financial flows.

Table 2 demonstrates key guidelines of social and economic and scientific-technical development of the Sverdlovsk region that have formed the basis for prediction models of the shadow sector of economy.

Figure 6 demonstrates prediction scenarios of variation of the damage to the economic system of the region until 2020.

The data of table 2 and figure 6 provide a conclusion that adverse effect of shadow economic activity on the economic system of the Sverdlovsk region will reduce in the near future, and an extent of such reduction will depend on an economic development scenario choice.

In the issue of the research work a complex of steps aimed at reduction of the shadow segment in the medium and long term has been developed. The projected steps are grouped into three main blocks given further.

\section{Stimulation of investment activity as an element of the state policy aimed at shadow activity reduction.}

As was demonstrated by the prediction results, stimulation of investment activity forms a basis for successful implementation of the optimistic scenario of socio-economic development, according to which the level shadow economy decreases faster in comparison to other scenarios. Thereupon, the following state policy measures are considered urgent: 
Basic prediction guidelines of socio-economic and scientific-technical development of the Sverdlovsk region until 2020

\begin{tabular}{|c|c|c|c|c|}
\hline \multirow{2}{*}{ Rate } & \multicolumn{4}{|c|}{ Prediction period } \\
\hline & 2008-2010 & 2011-2015 & $2016-2020$ & $2008-2020$ \\
\hline \multicolumn{5}{|c|}{ GRP per capita, comparable prices, thousand rubles } \\
\hline Inertia scenario & 229.3 & 345.1 & 549.6 & 549.6 \\
\hline Innovation scenario & 237.5 & 383.9 & 732.8 & 732.8 \\
\hline Optimistic scenario & 242.9 & 413.2 & 940 & 940 \\
\hline \multicolumn{5}{|c|}{ Capital investment (accumulated during the period), comparable prices, billion rubles } \\
\hline Inertia scenario & 689.1 & 1822.50 & 3158.50 & 5670.1 \\
\hline Innovation scenario & 724.5 & 2177.70 & 4464.90 & 7367.1 \\
\hline Optimistic scenario & 781.9 & 2666.10 & 6237.60 & 9685.6 \\
\hline \multicolumn{5}{|c|}{ Annual average growth rate of the high-technology sector, \% } \\
\hline Inertia scenario & 110.1 & 110.4 & 108.8 & 109.7 \\
\hline Innovation scenario & 111.5 & 112.1 & 116 & 113.5 \\
\hline Optimistic scenario & 112.3 & 113.3 & 122.3 & 116.4 \\
\hline \multicolumn{5}{|c|}{ Share of the high-technology sector in the GRP by the end of the period, \% } \\
\hline Inertia scenario & 17 & 18.2 & 19 & 19 \\
\hline Innovation scenario & 18.1 & 19.8 & 22 & 22 \\
\hline Optimistic scenario & 18.1 & 19.8 & 24 & 24 \\
\hline \multicolumn{5}{|c|}{ Growth rate of economy sector employees, \% } \\
\hline Inertia scenario & 99.5 & 99.2 & 99.2 & 97.9 \\
\hline Innovation scenario & 100.7 & 101.2 & 101.2 & 103.1 \\
\hline Optimistic scenario & 102.3 & 103.8 & 103.8 & 110.2 \\
\hline \multicolumn{5}{|c|}{ Number of economy sector employees by the end of the period, thousand people } \\
\hline Inertia scenario & 2081.9 & 2065.3 & 2048.5 & 2048.5 \\
\hline Innovation scenario & 2107 & 2132.3 & 2157 & 2157 \\
\hline Optimistic scenario & 2140.5 & 2221.9 & 2306.8 & 2306.8 \\
\hline \multicolumn{5}{|l|}{ Population development rate, $\%$} \\
\hline Inertia scenario & 99.6 & 99.8 & 99.9 & 99.3 \\
\hline Innovation scenario & 99.7 & 100.3 & 100.5 & 100.4 \\
\hline Optimistic scenario & 99.7 & 100.3 & 100.4 & 100.4 \\
\hline \multicolumn{5}{|c|}{ Consolidated budget of the region, comparable prices, billion rubles } \\
\hline Inertia scenario & 160.7 & 241.4 & 384 & 384 \\
\hline Innovation scenario & 166.6 & 270.1 & 517.7 & 517.7 \\
\hline Optimistic scenario & 170.5 & 290.9 & 664.4 & 664.4 \\
\hline \multicolumn{5}{|l|}{ Actual growth rate of wages, $\%$} \\
\hline Inertia scenario & 124.5 & 151.7 & 160.2 & 302.3 \\
\hline Innovation scenario & 127.5 & 159.8 & 189.5 & 387.1 \\
\hline Optimistic scenario & 128.5 & 164.4 & 220 & 464.7 \\
\hline
\end{tabular}

1. Enhancement of investment appeal for foreign investors:

1.1. Enhancement of taxation referred to securities trading (adjustment of legislation to the presentday standards that regulate taxation of transactions; to financial tools of regulation of profit tax deduction in terms of securities transactions by foreign shareholders; specification of the procedure of market price-setting for securities with a view of profit tax application).
1.2. Expansion of the list of profit tax-free foreign investors in investment unattractive sectors of economy.

2. Stimulation of investment into sectors and industries with a long pay-back period:

2.1. Enhancement in terms of granting profit tax holidays and investment tax credits, transfer of relative administration functions to the RF subjects. 
2.2. Application of mineral replacement tax privileges referred to low-profitability deposits with extended period of development.

2.3. Introduction of profit tax and wealth tax privileges regarding equipment applied for construction of a social, municipal and transport infrastructure, as well as networks. Tax exemption in terms of income realized in favor of municipal or state ownership.

II. Stimulation of innovation activity as an element of the state policy aimed at shadow activity reduction.

Steps aimed at shadow activity reduction should include stimulation of innovation activity, so far as transformation of scientific-technical level of industrial production will promote capital renewals and, therefore, rise in yield of capital investments, labor productivity and economic profitability, as well as production standards and business enhancement. The specified factors are key for shadow activity reduction.

The steps aimed at stimulation of innovation activity planned within the framework of the Government order "Key guidelines of the tax policy in the Russian Federation for 2011 and the planning period of 2012 and 2013" are unfortunately oriented chiefly to adjustment the taxation mechanisms. In this connection, expansion of the given mechanisms is required by way of introduction of more efficient measures, namely:

1. Preferential treatment of foreign economic activities in terms of VAT.

2. Exemption from the wealth tax for innovation-oriented enterprises.

3. Exemption from the wealth and transport tax relative to hi-tech equipment and energy- and fuelefficient vehicles.

4. Exemption from the profit tax for the period of introduction of innovative products.

5. Enhancement of depreciation policy referred to equipment applied for innovations.

III. Reduction of shadow economy level in the activity of small enterprises.

So far as small enterprises are the category of taxpayers that is most liable to shadow activities, in- troduction of measures aimed at official economic activity enhancement is required. In particular, enhancement of specific tax treatment is a priority:

1. Retention of current economic restrictions on application of specific tax treatment in favor of privilege enhancement (exemption from social transfers or reduction of tax load to the former level $-26 \%$ ).

2. Elimination of duplication in the list of economic activities subject to different types of tax treatment (the matter concerns a simplified tax system based on a patent and the unified tax on imputed income).

3. Simplification of tax administration mechanisms of small enterprises, including enhancement of electronic accounting tools.

On the basis of the analysis of shadow economy impact on the economic system of the region, a conclusion can be drawn that the shadow economy (as was already mentioned) is a touchstone responding to an economic condition. Shadow economy is an economic phenomenon that cannot be eliminated completely, but provided correct and timely measures are taken, minimization of its negative influence is possible.

\section{References}

1. Agarkov, G. A. (2008). Shadow economy impact on socioeconomic development of a region. USTU-UPI Bulletin. № 1. C. 75-79. (Экономика и управление).

2. Agarkov, G. A., Naydyonov, A. S., Chusova, A. E. (2009). Socio-economic effect of the world economic crisis on the shadow sector of economy of the region. Economy of region, 4. pp. 207-210.

3. Korshunov, L. A., Bystrai, G. P., Ohotnikov, S. A., Lykov, I. A., Nikulina, N. L. (2010). Nonlinear dynamics techniques as applied to analysis and prediction of regional economic systems. Journal of economic theory, 3. pp. 103-114.

4. Agarkov, G. A., Naydyonov A. S. (2009). Enhancement of efficiency of tax audits as a priority in terms of upgrading of the tax administration system. Economics. Taxes. Law, 6. pp. 4-13.

UDC: 332.05:333.9

keywords: shadow economy, prediction, regional economy, the Sverdlovsk region 